\title{
Electrical and thermal properties of PLA/CNT composite films
}

\author{
Thayara Ceregatti ${ }^{1}$, Paloma Pecharki ${ }^{1}$, Wagner M. Pachekoski ${ }^{2}$ \\ Daniela Becker ${ }^{1}$, Carla Dalmolin ${ }^{1 *}$
}

\author{
${ }^{1}$ Centro de Ciências Tecnológicas - CCT, Universidade do Estado de Santa Catarina - UDESC \\ e-mail: carla.dalmolin@udesc.br \\ thay.ceregatti@gmail.com; palomapecharki@gmail.com; daniela.becker@udesc.br; \\ ${ }^{2}$ Centro Joinville, Universidade Federal de Santa Catarina - UFSC \\ e-mail: wagner.pachekoski@ufsc.br
}

\begin{abstract}
Conducting polymers presents many potential applications such as biosensors and biofuelcells. However, to be used in those devices, a thin film must be deposited onto a conducting and biocompatible substrate. In this work, carbon nanotubes (CNT) were mixed in a poly (lactic acid) - PLA - matrix with different compositions (from 0.25 to $5.0 \%$ ) in order to form conducting composites suitable to the deposition of a conducting polymer. Thermal properties of PLA/CNT composites were evaluated by Thermogravimetry (TG) and Differenctial Scanning Calorimetry (DSC), and the electrical properties were evaluated by 2-probe method and by Electrochemical Impedance Spectroscopy (EIS). Thermal analysis showed and influence of CNT quantities on PLA crystallization, which also showed an influence on conductivity of the tested materials. Besides, the conductivity of PLA/NTC 1\% film showed similar values of the conducting polymer (Pani) itself.
\end{abstract}

Keywords: poly (lactic acid), carbon nanotubes, electrical properties, conducting polymers.

\section{INTRODUCTION}

Polyaniline (Pani) is a conducting polymer largely studied for applications such as biosensors, supercapacitors, organic cells, etc., due to their reversible oxidation/reduction reactions, high theoretical capacity and the possibility to prepare thin and flexible films [1]. For all those applications, a thin film must be deposited onto a conducting substrate. On the other hand, deposition of Pani onto a biomaterial is interesting for its use in biosensors and biofuel cells. In this case, substrate must be a biocompatible material with good mechanical properties to support the conducting polymer film and, also, some conductivity is necessary in order to guarantee the electrical contact for redox reactions. Several composites have been proposed as substrates to improve Pani performance and mechanical properties. However, conducting composites of biodegradable, biocompatible polymer and carbon nanotube seems to be the most attractive for a polyaniline-based biosensor [2].

Poly (lactic acid) - PLA - is a biodegradable polymer synthesized from renewable resources through bioconversion and polymerization, known for its ease processability and it is already commercially available. PLA based composites are receiving more attention, such as the investigation of the morphological and electrical properties of different PLA based polymer composites. But then, carbon nanotubes (CNTs) have gained main interest as nanofillers due to their high electric and thermal conductivity. Taking advantage of their electrical conductivity, some authors have attempted using CNTs to elaborate conductive PLA-based nanocomposites [3]. Low percolation thresholds have been achieved, corresponding to the formation of a conductive network structure within the PLA, by establishing a relation between the aspect ratio of carbon nanotubes and the formation of percolating networks in PLA/CNT nanocomposites in terms of rheology, electrical conductivity and mechanical properties. The final properties of those PLA composites not only depend on the filler dispersion and concentration, but also on dimensional structure of particles themselves [4,5].

In this work, CNTs were mixed in a poly (lactic acid) - PLA - matrix with different compositions (from 0.25 to $5.0 \%$ ) in order to form conducting composites suitable to polyaniline deposition. PLA/CNT composites were studied through thermal analysis (Thermogravimetry and Differential Scanning Calorimetry), Scanning Electron Microscopy and Electrochemical Impedance Spectroscopy in order to understand the effect of NTC dispersion in the PLA matrix. Pani was deposited onto PLA/CNT substrate by chemical 
polymerization of aniline, and its adherence and electrochemical properties were evaluated.

\section{MATERIALS AND METHODS}

Multiwall carbon nanotubes, named as CNT, were provided by Chengdu Organic Chemicals Co. and characterized in previous works [6]. Poly(lactic acid) - PLA - (Ingeo 3251D) was provided by the company NatureWorks®; and Aniline (VETEC) was distilled under vacuum prior to use. All other chemicals were reagent grade and used as received.

PLA/CNT nanocomposites samples were produced with different filler contents: $0.25 \% ; 0.50 \%$; $0.75 \% ; 1.0 \% ; 2.0 \%$ and $5.0 \%(\mathrm{~m} / \mathrm{m})$. The melt mixing process was performed in a Haake torque rheometer with a $50 \mathrm{~cm} 3$ mixing chamber and standard rotors, operated at $120^{\circ} \mathrm{C}$ and $50 \mathrm{rpm}$ for 10 minutes. The nanocomposites were compressed and molded using a hydraulic press at $120^{\circ} \mathrm{C}$ for 5 minutes by applying a pressure of $16 \mathrm{MPa}$ and cooled with water to room temperature to produce films with thickness of $0.30 \pm 0.02$ $\mathrm{mm}$.

Polyaniline was synthetized by oxidative polymerization of aniline (VETEC, distilled under reduced pressure) carried out in a $0.5 \mathrm{M}$ aqueous solution of $\mathrm{H}_{2} \mathrm{SO}_{4}$ and $0.2 \mathrm{M}$ of ammonium persulfate $-\left(\mathrm{NH}_{4}\right)_{2} \mathrm{~S}_{2} \mathrm{O}_{8}$ - (VETEC), while the reaction temperature was kept at $0 \sim 5^{\circ} \mathrm{C}$ using an ice water bath, and the reaction time was fixed at $5 \mathrm{~h}$ [7]. The resulting PANI powder were dried in for $24 \mathrm{~h}$ after being washed with deionized water and used for conductivity tests in order to compare with results for PLA/CNT films.

The melting and crystallization temperature and crystallinity degree were obtained by differential scanning calorimetry (DSC), in a Netzsch DSC $200 \mathrm{~F} 3$ device. The samples were heated from $25^{\circ} \mathrm{C}$ to $200^{\circ} \mathrm{C}$ at a rate of $10^{\circ} \mathrm{C} / \mathrm{mim}$, held at that temperature for $2 \mathrm{~min}$, then air cooled to $-10^{\circ} \mathrm{C}$ (cooling rate of $80^{\circ} \mathrm{C} / \mathrm{mim}$ ) before second heating scan from $-10^{\circ} \mathrm{C}$ to $200^{\circ} \mathrm{C}$ at $10^{\circ} \mathrm{C} / \mathrm{mim}$ (under nitrogen atmosphere). All the thermal parameters were determined from second heating scans. The crystallinity degree (Xc) was determined as show in Garlotta [8]. The weight loss was obtained by thermogravimetric analysis (TG), in a Netzsch STA $449 \mathrm{C}$ device with a heating rate of $10^{\circ} \mathrm{C} / \mathrm{min}$ from $25^{\circ} \mathrm{C}$ to $600{ }^{\circ} \mathrm{C}$ (under nitrogen atmosphere). A Jeol JSM-6710F Field emission electron microscope was used for morphological studied. The samples were fractured under liquid nitrogen and the surfaces were coated with gold to avoid charge by the electron beam. Room temperature DC conductivity measurements were performed using a two-probe method. AC conductivity was also measured by Electrochemical Impedance Spectroscopy using an AUTOLAB PGSTAT20 potentiostat / galvanostat with a frequency analyzer (FRA). The blocking electrode method was used, where a thin film was inserted between two stainless steel electrodes at open circuit potential, as shown in Figure 1. A DC perturbation of $10 \mathrm{mV}$ (r.m.s.) was applied in the frequency range of $1 \mathrm{~Hz}$ to $10 \mathrm{kHz}$. The specific conductance (conductivity) was calculated by normalizing the conductance with the contact area of the electrodes $(\mathrm{S}=3,14 \mathrm{~cm} 2)$ and sample thickness $(1=0.30 \mathrm{~mm})$.

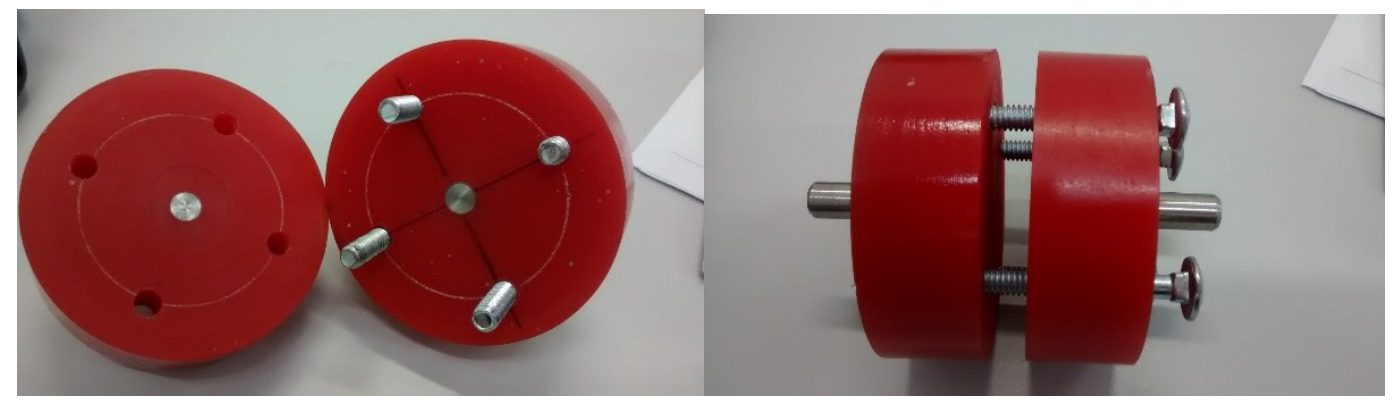

Figure 1: Electrochemical cell built for EIS and two-probe measurements. Sample is centered in contact with stainless steal electroctes (at left) and when the cell is closed (at right), working and reference terminals are plugged on both steal connectors.

\section{RESULTS AND DISCUSSION}

PLA/CNT nanocomposites with different compositions were characterized by morphology and also by thermal and electrical methods in order to choose the best substrate for Pani deposition. Main results are show below. 


\subsection{Morphology}

Figure 2 shows FEG micrographs for PLA/CNT nanocomposites. The quantity of CNT increases proportionally to the nanocomposites composition, and samples presented a homogenous morphology, with apparent good distribution and small carbon nanotubes agglomerates.

(a)
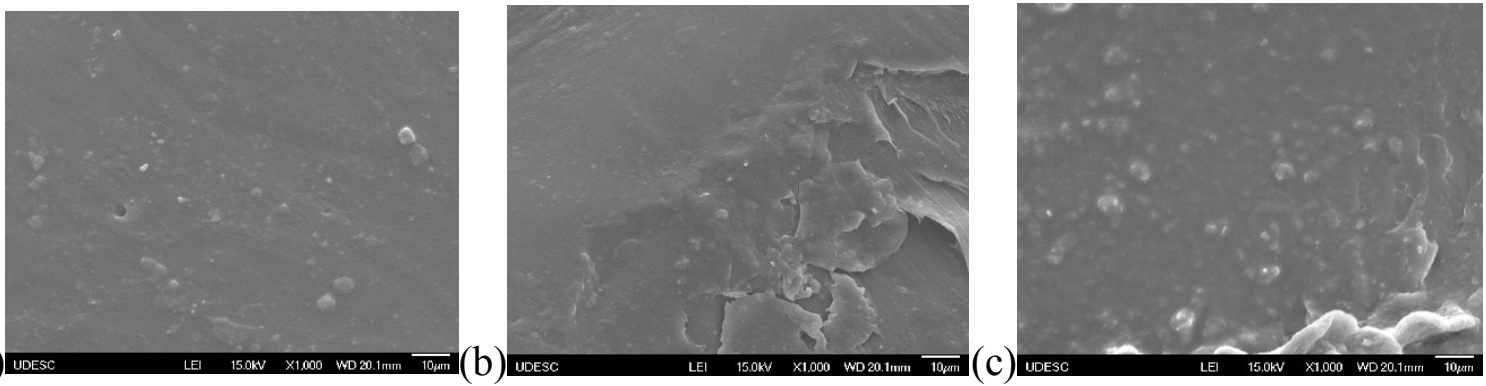

(d)
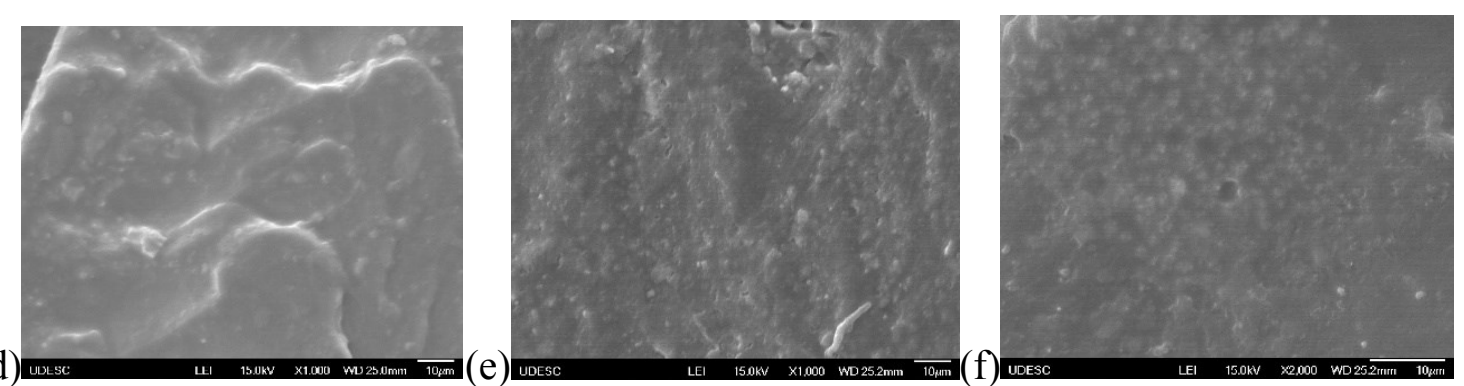

Figure 2: FEG micrographs at $1000 x$ of PLA/CNT varying CNT concentration. (a) $0.25 \%$; (b) $0.50 \%$; (c) $0.75 \%$; (d) $1.0 \%$; (e) $2.0 \%$ and (f) $5.0 \%$.

\subsection{Thermal Characterization}

Figure 3 shows DSC results for PLA/CNT composites with higher CNT compositions (1.0\%, 2.0\% and $5.0 \%$ ), when main differences are better visualized. Thermal properties, including crystallinity, glass transition temperatures $(\mathrm{Tg})$, crystallization and melting temperatures (Tc1, Tc2 and $\mathrm{Tm}$ ) are quantified in Table 1 and compared with neat PLA, already studied in our group[9].

Table 1: Thermal properties measured by DSC for neat PLA and PLA nanocomposites.

\begin{tabular}{c|c|c|c|cc}
\hline Nanocomposites & $\left.\mathrm{T}_{\mathrm{g}}{ }^{\circ} \mathrm{C}\right)$ & $\mathrm{T}_{\mathrm{c} 1}\left({ }^{\circ} \mathrm{C}\right)$ & $\mathrm{T}_{\mathrm{c} 2}\left({ }^{\circ} \mathrm{C}\right)$ & $\mathrm{T}_{\mathrm{m}}\left({ }^{\circ} \mathrm{C}\right)$ & $\mathrm{X}_{\mathrm{c}}(\%)$ \\
\hline PLA & 59 & 99 & 155 & 168 & 9 \\
PLA/CNT 1\% & 61 & 100 & 155 & 170 & 10 \\
PLA/CNT 2\% & 60 & 100 & 153 & 170 & 12 \\
PLA/CNT 5\% & 62 & 108 & - & 172 & 19 \\
\hline
\end{tabular}

No significant modifications where observed in the Tg and Tm of PLA with the carbon nanotube addition. On the other hand, CNT contend showed an influence in crystallization, especially in the PLA/CNT 5\% composition. PLA presents two crystallization temperatures, the second one right before Tm, assigned as recrystallization of imperfect crystals to more perfect ones [10]. This behavior was also observed for compositions with $1 \%$ and $2 \%$ of CNT. Nevertheless, when a higher quantity of nanofiller was added (5\%), second Tc disappear, indicating that polymer matrix doesn't have enough mobility to recrystallization into the wider and more perfect crystalline regions. The slightly but consistent increase in Tg and Tm for PLA/CNT 5\% nanocomposite may corroborate the assumption of low polymer chain mobility when higher concentrations of nanofillers are present. 


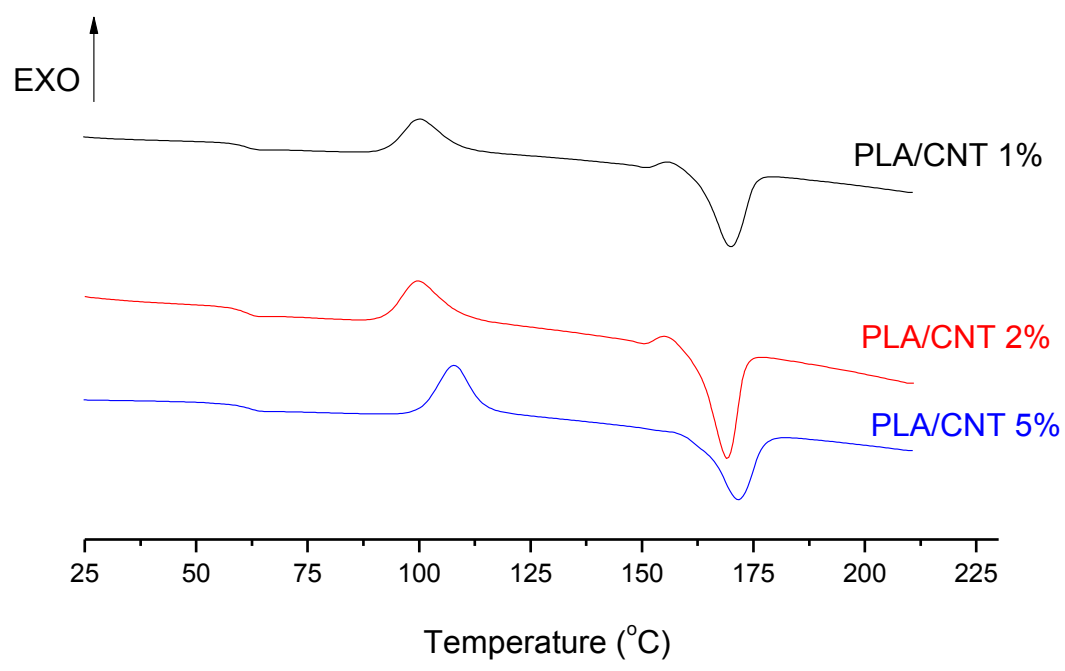

Figure 3: DSC profiles for PLA/CNT nanocomposites with 1.0\%, $2.0 \%$ and $5 \%$ compositions.

Also, crystallization degree of PLA increases with the CNT content in the nanocomposites. Higher concentration of nanofiller could mean a higher concentration of nucleating agent, which promotes higher quantities of cristallyzation nuclei and increasing the crystallization degree. In other words, DSC profiles of the nanocomposites indicates that CNT is acting as a nucleating agent for PLA matrix.

Figure 4 presents the onset degradation temperature (Tonset) obtained by thermogravimetric analyses. There is an increase on degradation temperature when neat PLA and PLA/CNT nanocomposites are compared, but no relation could be established with CNT concentration in the three studied compositions. An increase in the thermal stability of PLA is expected in PLA/CNT nanocomposites when CNT dispersion and distribution in the polymeric matrix can build an interconnected structure that provides a thermally conductive path, responsible for an interfacial thermal resistance and energy dispersion [11].

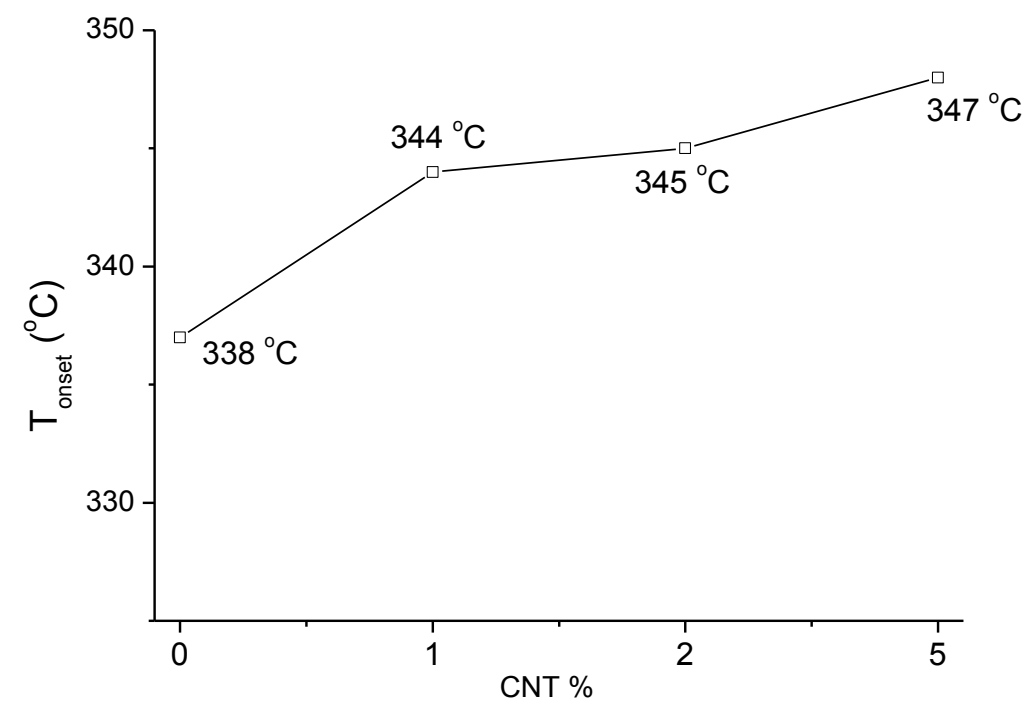

Figure 4: Onset degradation temperature for PLA nanocomposites obtained by TG.

\subsection{Electrical Characterization}

Conductivity of nanocomposites, PLA and Pani alone were evaluated by two methods: two-probe, for DC conductivity and Impedance Spectroscopy for AC conductivity. For compositions with $0.25 \% ; 0.50 \%$ and $0.75 \%$ of CNT and pure PLA, samples were so resistive that the low current measured was under the limits 
of the equipment. Results for compositions with higher content of CNT, where percolation was achieved, are given below.

Figure 5 shows the shifting of the DC conductivity of PLA/CNT nanocomposites with the content of CNT. Although the presence of CNT have contributed with electrical conductivity with quantities of $1 \%$ or higher, the increase of CNT content in the samples drastically decreases their electrical conductivity. This behavior is seen for PLA/CNT $2 \%$ and PLA/CNT 5\%. On the other hand, PLA/CNT $1 \%$ presents a conductivity of $44 \mathrm{mS} / \mathrm{cm}$, as higher as Pani itself, which was measured as $50 \mathrm{mS} / \mathrm{cm}$ in the same conditions.

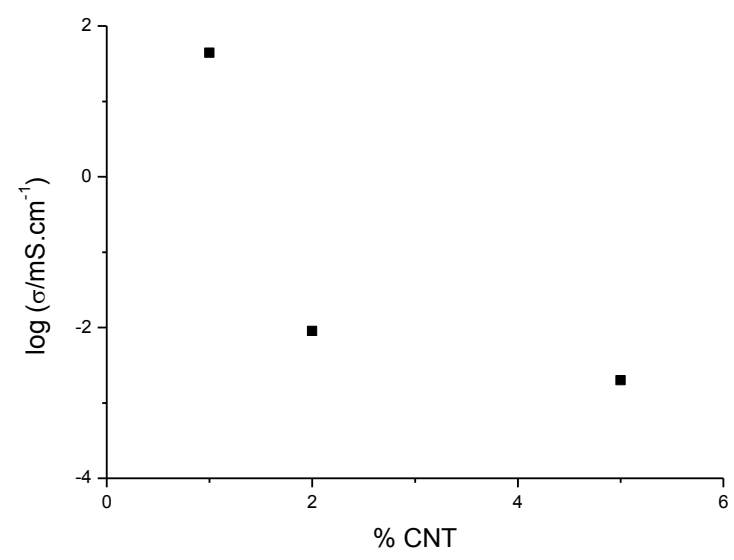

Figure 5: DC conductivity of PLA/CNT nanocomposites with different compositions.

Similar behavior was observed in the AC impedance spectra. Figure 6 shows Bode plots (impedance module vs. frequency) for PLA/CNT nanocomposites and polyaniline. Both Pani and PLA/CNT nanocomposites behaves as pure resistors at low frequencies, where impedance is constant in this frequency region. This means that both Pani and PLA/CNT substrates promote electron flow with low resistance when a potential difference is applied. The behavior expected for insulating polymers such as PLA would be similar as a capacitor, where the potential applied between two electrodes would promote polarization, and a linear decrease of impedance with frequency [12].

(a)

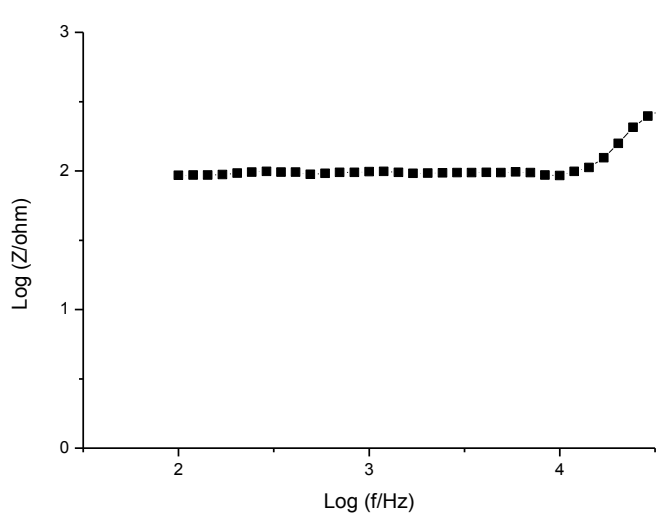

Figure 6: Bode plots ( $\log Z$ vs. $\log$ f) for (a) polyaniline and (b) PLA/CNT nanocomposites.

Conductivity of these materials were calculated by considering sample dimensions. The value found for Pani was $90 \mathrm{mS} / \mathrm{cm}$, as for PLA/CNT $1 \%$ and PLA/CNT $5 \%$ was $85 \mathrm{mS} / \mathrm{cm}$ and $0.20 \mathrm{mS} / \mathrm{cm}$, respectively.

By conductivity results, it is possible to assume there is a minimum quantity of $1 \%$ of CNT in the PLA matrix to promote electron flow. However, above this limit, the material conductivity decreases. SEM and TG results have indicated a relatively homogenous surface and interconnected structure, that it would be 
expected to promote electrical conduction. On the other hand, DSC results have showed that CNT is acting as a nucleating agent, and nanocomposites with higher concentration of nanofiller presented higher crystallization degree and low chain mobility. Somehow, the benefic effect of CNT on the electrical conductivity in PLA nanocomposites is hindered by its effects on the polymeric matrix, specially when higher quantities of CNT are added.

Based on conductivity results, PLA/CNT 1\% nanocomposite was chosen as substrate for chemical deposition of Pani. The electric conductivity of this nanocomposite found for two probe method and EIS was $46 \mathrm{mS} / \mathrm{cm}$ and $85 \mathrm{mS} / \mathrm{cm}$, respectively. Since conductivity results were similar for both Pani itself as Pani deposited onto PLA/CNT 1\%, it is expected that this nanocomposite may act as a conducting polymer electrode for polyaniline applications.

\section{CONCLUSIONS}

Nanocomposites of PLA and CNT were produced with different compositions aiming a good substrate for polyaniline deposition, which can keep the conductivity properties of the conducting polymer. Thermal and morphological studies show significant modifications on the PLA matrix with higher CNT contents, indicating an influence of polymer crystallization on the electrical properties of the nanocomposites.

Measurable values of electrical conductivity could be achieve only on nanocomposites with CNT concentration above $1 \%$. However, in the higher concentrations, there is a decrease in the material conductivity, probably to CNT effect on the PLA crystallization and chain mobility.

Based on these results, PLA/CNT 1\% nanocomposite was chosen for polyaniline deposition, showing a similar electric behavior of the pure conducting polymer.

\section{ACKNOWLEDGMENTS}

Authors acknowledge EMBRAPA for PLA donation and the financial support by UDESC, FAPESC and CNPq.

\section{BIBLIOGRAFIA}

[1] JANÁKY, C., VISY, C. “Conducting polymer-based hybrid assemblies for electrochemical sensing: a materials science perspective”, Analytical and Bioanalytical Chemistry, v. 405, pp. 3489-3311, 2013.

[2] MILAKIN, K. A., KOROVIN, A. N., MOROZ, E. V., et al., "Polyaniline-Based Sensor Material for Potentiometric Determination of Ascorbic Acid", Electroanalysis, v. 25, pp.1323-1330, 2013.

[3] RAQUEZ, J. -M., HABIBI,Y., MURARIU, M., et al., "Polylactide (PLA)-based nanocomposites", Progress in Polymer Science, v. 38, pp.1504-1542, 2013.

[4] LI, Y., LIU, H., DAI, K., et al., "Tuning of vapor sensing behaviors of eco-friendly conductive polymer composites utilizing ramie fiber”, Sensors and Actuators B: Chemical, v. 31, pp.1279-1289, 2015.

[5] WU, D., LY, Q., FENG, S., et al., "Polylactide composite foams containing carbon nanotubes and carbon black: Synergistic effect of filler on electrical conductivity”, Carbon, v. 95, pp.380-387, 2015.

[6] BELLO,R. H. Efeitos da funcionalização química em nanotubos de carbono e nanoplateletes de grafeno por silanização em matriz epóxi. Dissertação de M.Sc., Universidade do Estado de Snata Catarina - UDESC, Joinville, Santa Catarina, Brasil, 2015.

[7] WANG, J., LIU, X., CHOI, H. -S., et al., "Conducting polymer films fabricated by oxidative graft copolymerization of aniline on poly(acrylic acid) grafted poly(ethylene terephthalate)", Journal of Physics Chemistry B, v. 112, pp.14829-14835, 2008

[8] GARLOTTA, D., "A literature review of poly(lactic acid)", Journal of Polymers and the Environment, v. 9, pp. 63-84, 2001.

[9] DECOL, M., Nanocompósitos de poli(ácido lático), poli(e-caprolactona) e nanotubos de carbono. Dissertação de mestrado, Universidade do Estado de Snata Catarina, UDESC, Joinville, Santa Catarina, Brasil, 2015.

[10] LÓPEZ-RODRIGUEZ, N., LÒPEZ-ARRAIZA, A., MEAURIO, E., et al., "Crystallization, morphology, and mechanical behavior of polylactide/poly(E-caprolactone) blends", Polymer Engineering \& Science, v. 46, pp. 1299-1308, 2006. 
[11] LIZUNDIA, E., SARASUA, J. R., D'ANGELO, F., et al., "Biocompatible poly (L-lactide) / MWCNT nanocomposites: morphological characterization, electrical properties, and stem cell interaction", Macromolecular Bioscience, v. 12, pp. 870-881, 2012.

[12] LAREDO, E., GRIMAU, M., BELLO, A., et al., “AC conductivity of selectively locate carbon nanotubes in polylactide nanocomposites", Biomacromolecules, v. 11, pp. 1339-1347, 2010. 